\title{
Effectiveness of Safety Interventions in Fire Engines to Reduce Potential Airborne Transmission of SARS-CoV-2
}

\author{
Elmar Bourdon ${ }^{1,2, *}$, Thomas Schaefer ${ }^{3}$, Maximilian Kittel ${ }^{4}$, Matthias Raedle ${ }^{3} \mathbb{D}$ and Alexandra Heininger 5 \\ 1 Institute of Medical Technology, Heidelberg University and Mannheim University of Applied Sciences, \\ Theodor-Kutzer-Ufer 1-3, D-68167 Mannheim, Germany \\ 2 Community Fire Department, Muehlenweg 5-7, D-68549 Ilvesheim, Germany \\ 3 Center for Mass Spectrometry and Optical Spectroscopy (CeMOS), Mannheim University of Applied Sciences, \\ Paul-Wittsack-Str. 10, D-68163 Mannheim, Germany; t.schaefer@hs-mannheim.de (T.S.); \\ m.raedle@hs-mannheim.de (M.R.) \\ 4 Department of Clinical Chemistry, University Medical Center Mannheim, Medical Faculty Mannheim of \\ Heidelberg University, Theodor-Kutzer-Ufer 1-3, D-68167 Mannheim, Germany; maximilian.kittel@umm.de \\ 5 Hygiene Department, University Medical Center Mannheim, Theodor-Kutzer-Ufer 1-3, \\ D-68167 Mannheim, Germany; alexandra.heininger@umm.de \\ * Correspondence: elmar.bourdon@medtech.uni-heidelberg.de; Tel.: +49-621-383-5602
}

Citation: Bourdon, E.; Schaefer, T.; Kittel, M.; Raedle, M.; Heininger, A. Effectiveness of Safety Interventions in Fire Engines to Reduce Potential Airborne Transmission of SARS-CoV-2. Fire 2021, 4, 98. https://doi.org/10.3390/ fire 4040098

Academic Editor: Alistair M. S. Smith

Received: 29 October 2021

Accepted: 15 December 2021

Published: 19 December 2021

Publisher's Note: MDPI stays neutral with regard to jurisdictional claims in published maps and institutional affiliations.

Copyright: (c) 2021 by the authors. Licensee MDPI, Basel, Switzerland. This article is an open access article distributed under the terms and conditions of the Creative Commons Attribution (CC BY) license (https:/ / creativecommons.org/licenses/by/ $4.0 /)$.

\begin{abstract}
Physical distancing and wearing a face mask are key interventions to prevent COVID-19. While this remains difficult to practice for millions of firefighters in fire engines responding to emergencies, the delayed forthcoming of evidence on the effectiveness of such safety interventions in this setting presents a major problem. In this field experimental study, we provided initial evidence to close this gap. We examined total aerosol burden in the cabin of a fire engine whilst manipulating crew size, use of FFP2 respirators and use of SCBA full-face masks during 15-min driving periods. At the same time, we controlled for crew activity and speaking, vehicle speed, cabin ventilation, cabin air temperature, pressure and humidity. Limiting the crew size, using FFP2 respirators and not donning SCBA full-face masks was associated with a reduction of the arithmetic mean of total aerosol burden of up to $49 \%$. This study provided initial evidence on the effectiveness of safety interventions in fire engines to reduce potential airborne transmission of SARS-CoV-2 through aerosols. More research about the physical and the clinical effectiveness of such safety interventions is needed.
\end{abstract}

Keywords: SARS-CoV-2; COVID-19; fire engine; vehicle; aerosol reduction; fine dust measurement; infection control; FFP2 respirator mask; cabin crew; ventilation

\section{Introduction}

In 2018 the international association of fire and rescue services reported more than 14 million firefighters responding to almost 48 million calls in countries worldwide, reaching a total of three million fires. A large majority of these fire services were provided by volunteer firefighters, both in Germany and worldwide [1,2]. It is considered essential to maintain these critical infrastructures during the current coronavirus disease 2019 (COVID-19) pandemic with more than 263 million cumulative COVID-19 cases and more than 5 million deaths reported worldwide by November 2021 [3].

COVID-19 is caused by the severe acute respiratory syndrome coronavirus 2 (SARS$\mathrm{CoV}-2)$. Current evidence suggests that this virus spreads in small liquid particles from an infected person's mouth or nose when they cough, sneeze, speak or breathe heavily. These small liquid particles range from liquid aerosols (size $<5 \mu \mathrm{m}$ ) up to respiratory droplets (size $>5 \mu \mathrm{m}$ ). While bigger droplets fall to the ground quickly, small liquid aerosols can remain in the air for a long time and spread throughout a room. Transmission to other persons occurs when these small liquid particles get inhaled by a susceptive person or via contact with the mucous membrane in the eye or respiratory tract. This is more likely to 
happen when other persons are in close proximity to an infected person [4,5], while indoor situations are associated with particular and elevated risks of transmission [6-8].

Since December 2020, new coronavirus variants are rapidly emerging [9]. The latest epidemiological data suggest that these variants are associated with an increase in both transmissibility and mortality [10]. Consequently, physical distancing, wearing a face mask and ventilation are considered key safety interventions to prevent SARS-CoV-2 infections in indoor situations [6,7,11].

However, these interventions remain difficult to practice in fire engines responding to emergency calls. The vehicle cabin equals a tight indoor situation. In Germany, the minimum tactical crew size of a standard fire engine type Löschgruppenfahrzeug (LF) is 6 persons, while its standard tactical crew size is 9 persons [12], resulting in less than $1 \mathrm{~m}^{3}$ air volume in the cabin per person. The distance between crew members in the cabin is one meter and less. When approaching an incident, the crew is usually seated in the cabin for up to $15 \mathrm{~min}$. This situation is defined as a high-risk exposure [13]. In case of false alerting or cancellation during approach, the crew's period in the cabin may exceed $15 \mathrm{~min}$. Critical weather, outside noise interfering with required radio terminal communication or with tactical communication inside and other environmental conditions may limit or prevent the airing of the cabin through open windows.

Moreover, already donning the full-face inhalation mask of the self-contained breathing apparatus (SCBA) in the cabin while the fire engine is approaching presents a widely accepted standard to gain life-saving time. To maximize available air supply in smoke the SCBA's full-face inhalation mask is not connected to the high-pressure tank until entering the smoky area at the incident site. Consequently, these firefighters using SCBA continue breathing unfiltered cabin air and, thus, remain with no respiratory protection against SARS-CoV-2 during approach.

This situation presents a particular challenge for volunteer fire departments. They cannot operate with permanent fire engine crews or duty schedules to limit the spread of this virus among their staff. Instead, individuals forming a fire engine crew upon alert usually vary depending on their actual availability and arrival time at the fire station.

Against this background, a variety of COVID-19 safety interventions is practiced in fire engines responding to emergencies. These practices include the reduction of tactical crew size, the use of face-coverings, and ventilation as is felt appropriate or feasible.

We conducted a literature search to identify publications relevant to our study. The search included PubMed, the Cochrane-Library and Google Scholar, and covered a period from 2001 to 2021. Search terms used were SARS-CoV-2, COVID-19, Safety Intervention, Fire Engine, Vehicle, Aerosol, Infection Control, FFP2 Respirator Mask, Cabin Crew and Ventilation in multiple combinations. To date, there have been no data available on the effectiveness of those safety interventions in this specific setting, neither for a single COVID-19 safety intervention nor for a combination of different interventions. Research on the potential airborne transmission of SARS-CoV-2 in automobile settings is currently in its infancy. The few published studies to-date relate to aerosol dispersion in passenger cars and public transport buses, and collected laboratory and numerical modeling data [14-17]. Given the major differences of technical, human and environmental factors potentially determining aerosol emission and aerosol reduction, we found that this previous research did not capture the real-world situation inside a fire engine responding to an emergency. With millions of firefighters worldwide being in this high-risk exposure situation on every call, and their limited access to vaccination at present, this lack of evidence is considered a major issue.

While study subjects continued to be exposed to a potential infection with SARS-CoV-2 in family, occupational or public settings after the study, and exposing study subjects to a potential SARS-CoV-2 infection during the study would have been unethical, measuring the clinical effectiveness of COVID-19 safety interventions during this study was impossible. Moreover, there is insufficient reliable data to determine a critical concentration of 
infectious virus and a corresponding critical time period of exposure to exclude an airborne transmission of SARS-CoV-2 [18].

Therefore, we collected original data on effectiveness in a field experiment on 21 March 2021 using a novel ProxiCube NX 3 detector device in a pre-production ProxiCube-p design (Nevoox Europe GmbH, Mannheim, Germany) to investigate associations between combinations of COVID-19 safety interventions and total aerosol burden in a German standard fire engine responding to a mock fire emergency. Our aim was to provide initial evidence and to immediately translate it into initial guidance for decision making at the frontline of emergency response practice. Our study might also be relevant for responding to other respiratory diseases with similar modes of airborne transmission.

\section{Materials and Methods}

\subsection{Study Subjects and Safety}

Nine study participants were recruited from four different German fire departments through March 2021 and met the following criteria: completed basic training for fire service and SCBA use, fit for duty, no facial hair, active member of a German fire department, successful SARS-CoV-2 vaccination and no active SARS-CoV-2 infection. German volunteer firefighters on duty need to be aged 18 to 65 years. Study participants were aged as follows: $22,27,29,30,30,34,34,52$ and 57. Thus, the median of our sample was 30 and the arithmetic mean was 35 years of age.

The mobile COVID-19 test unit CoVLAB was used for SARS-CoV-2 diagnostics prior to experiment. CoVLAB is a 40-ton truck including an S2-safety laboratory with high-throughput molecular diagnostics technology, offering approximately $60 \mathrm{~min}$ from polymerase-chain-reaction (PCR)- and antibody-sampling to result [19].

The vaccination success was determined via an antibody assay against the spike protein (Elecsys Anti-SARS-CoV-2-S, Roche diagnostics, Mannheim, Germany) according to the manufacturer-specific cut off. Exclusion of an active SARS-CoV-2 infection was achieved via molecular genetic analysis of a combined nasopharyngeal swab using an IVD-labeled automated assay (Cepheid, Xpert Xpress SARS-CoV-2, Sunvalley, CA, USA).

The study was conducted in accordance with the Declaration of Helsinki and approved under the project identification code 2021-535-AF5 by the research ethics committee of the Medical Faculty Mannheim of Heidelberg University. All subjects gave their informed consent for inclusion before they participated in the study and all contributing fire departments approved participation of the subjects.

\subsection{Fire Engine and Experimental Setup}

Standard fire engines LF type are the most commonly used fire service vehicles in Germany and serve as a multipurpose resource for all types of incidents. Therefore, we used a German standard fire engine type LF 20 built to German standard 14530-11 of the Deutsches Institut für Normung e.V. (DIN 14530-11), manufactured in December 2014 by Albert Ziegler $\mathrm{GmbH}$, Germany on a Mercedes-Benz 1529 Atego $4 \times 2 / 4160$ chassis. The cabin included a total of nine seats, with two seats in the front and seven seats in the back area of the cabin. There was no wall or window separating the front area from the back area. Air volume of the cabin with nine persons seated was approximately $7.81 \mathrm{~m}^{3}$, thereof approximately $3.55 \mathrm{~m}^{3}$ in the front area and approximately $4.26 \mathrm{~m}^{3}$ in the back area. With just six persons seated in the cabin, approximate air volumes were $8.06 \mathrm{~m}^{3}, 3.55 \mathrm{~m}^{3}$ and $4.51 \mathrm{~m}^{3}$, respectively. Due to fragmented interior fitting and varying anatomy of study participants, we were not able to determine the air volume of the cabin exactly. The vehicle did not include an air-conditioning system. We switched mechanical ventilation of the cabin to $50 \%$ power. Air supply was switched to fresh air from outside and the air outlet was switched to instrument panel/windscreen. The air filter of the cabin ventilation system was standard as delivered ex works (Mercedes-Benz part no. A9738350147). The vehicle heating system was switched to the middle temperature setting. All cabin windows were closed. 
Figure 1 presents the seating in the cabin according to German fire service regulation Feuerwehrdienstvorschrift 3 (FwDV 3) [12]. The backrest of seats 3, 5, 7 and 8 included an SCBA pack for immediate donning during approach as shown in Figure 1 and Figure 3. The distance between individuals seated next to each other was less than one meter in every direction.

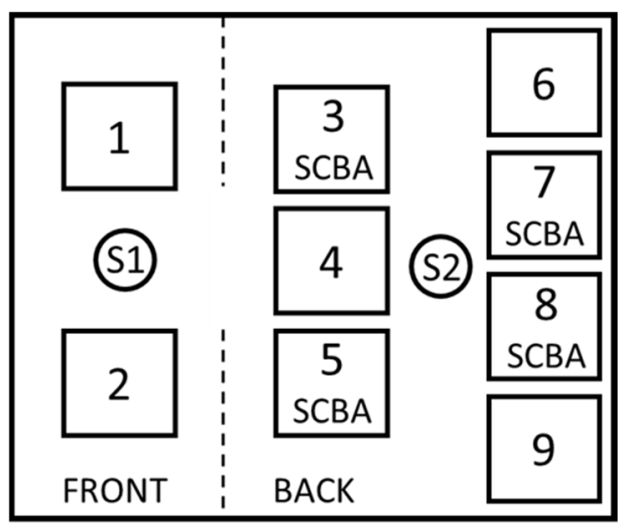

Figure 1. Seating of a standard tactical crew in LF 20 cabin with self-contained breathing apparatus (SCBA) on four seats and ProxiCube positions S1, S2.

In all experimental cases, every study participant wore a basic set of personal protective equipment according to German accident prevention regulation Unfallverhütungsvorschrift (UVV) Feuerwehren [20] including a fire helmet, firefighter turnout gear and safety boots. We used commercially available particle filtering half masks ZN9501 FFP2 NR (Anhui Zhongnan Air Defense Works Co. Ltd., Qianshan, China) according to European standard EN 149:2001+A1:2009 and CE-certified by CCQS Certification Services Ltd., Dublin, Ireland (Notified Body 2834).

\subsection{Aerosol Measurement Technology}

In order to measure dependent and control variables, we used two ProxiCube NX 3 detector devices (Nevoox Europe $\mathrm{GmbH}$, Mannheim, Germany) in a pre-production ProxiCube-p design as shown in Figure 2. The external dimensions of each device were $8 \times 8 \times 8 \mathrm{~cm}$ and both devices were supplied from the fire engine's electrical system using a 12V-USB-charging adapter. The devices were mounted at positions S1 and S2 in the fire engine's cabin as indicated in Figures 1-3. The vertical distance of S1 and S2 to the ceiling was $75 \mathrm{~cm}$ and $10 \mathrm{~cm}$, respectively.

Particle measurement was based on single particle detection by light extinction using Sensirion SPS30 particulate matter sensors [21]. These sensors are optical particle counters based on laser scattering. Moreover, the ProxiCube NX 3 detector devices included sensors for temperature, air pressure and humidity. The collected signal of the photodetector was converted in real-time into particle count $\left(\mathrm{P} \mathrm{cm}^{-3}\right)$ and mass concentration values $\left(\mu \mathrm{g} \mathrm{m}^{-3}\right)$. Sensor performance values are shown in Table 1 [21]. The airflow was approximately $0.015 \mathrm{~m}^{3} \mathrm{~h}^{-1}$ or $250 \mathrm{~mL} \mathrm{~min}^{-1}$ [22].

All dispersive events, i.e., both solid particles and liquid particles, were measured together. Each particle and droplet were measured and subsequently classified into the four size channels $<1 \mu \mathrm{m}, 1$ to $<2.5 \mu \mathrm{m}, 2.5$ to $<4 \mu \mathrm{m}$ and 4 to $10 \mu \mathrm{m}$. Particles or droplets that were larger than $10.0 \mu \mathrm{m}$ were not classified. Every aerosol value presented in this study is at any one time the sum of these four size channels. 


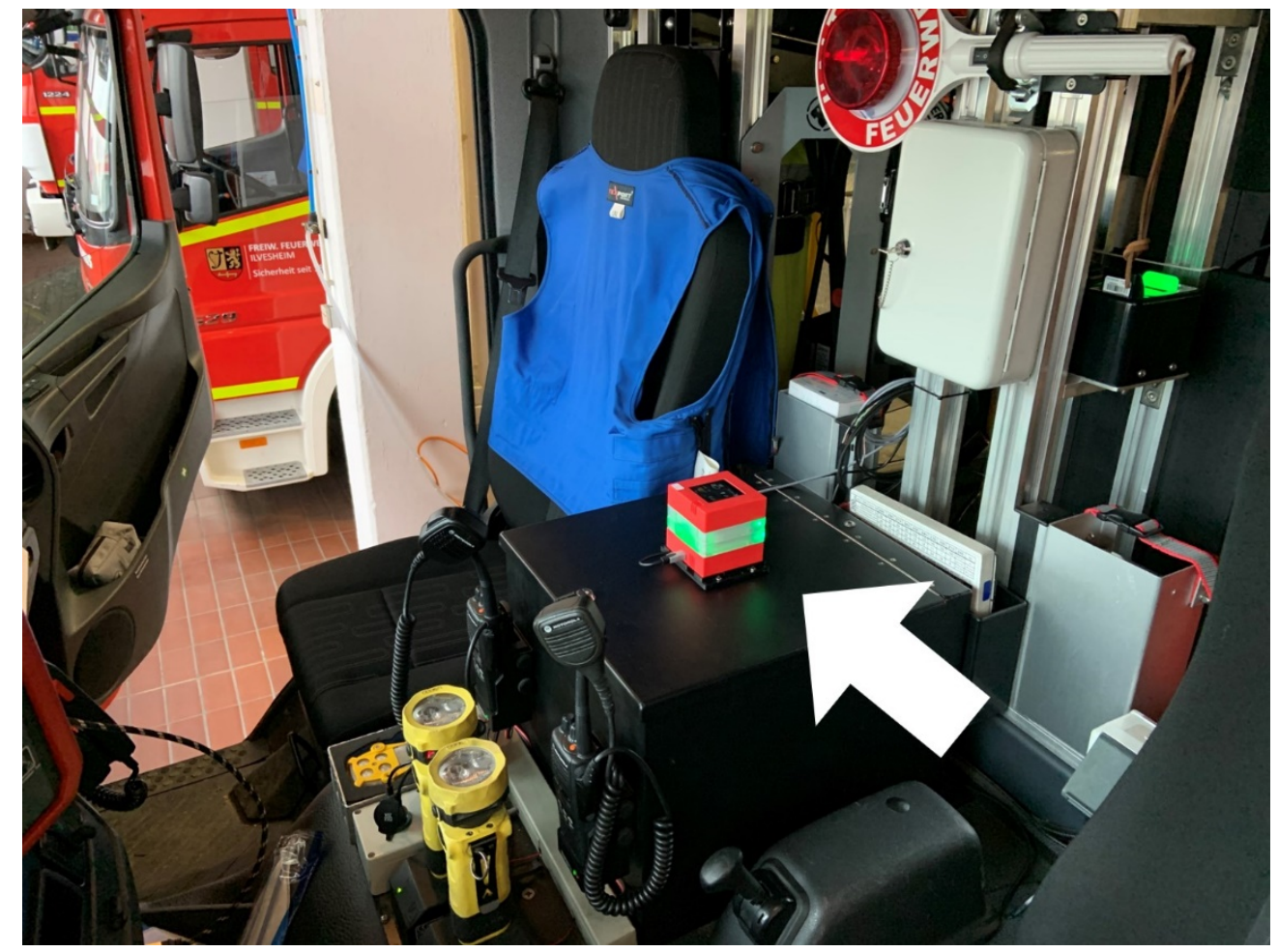

Figure 2. ProxiCube in front area position S1 (white arrow).

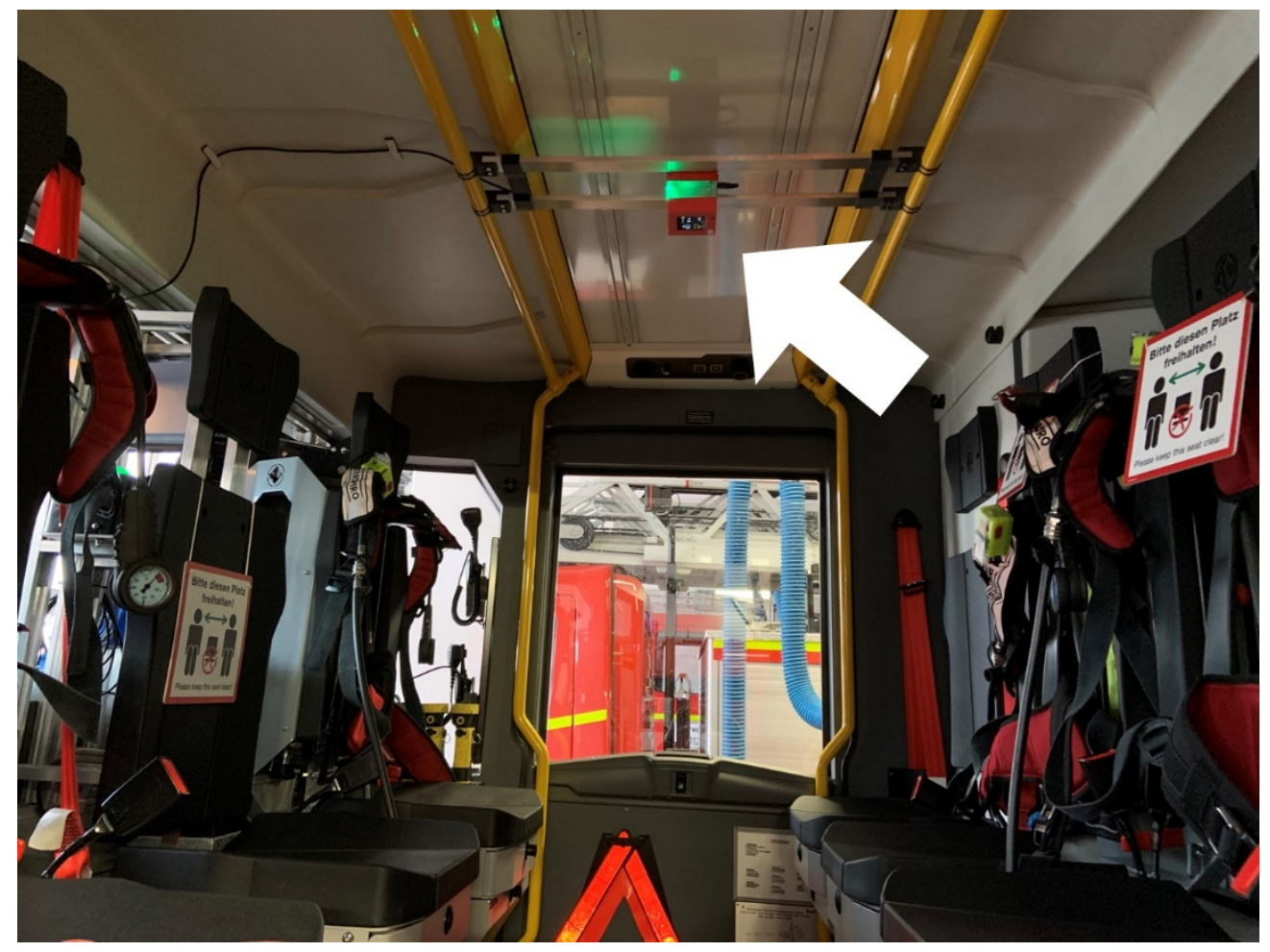

Figure 3. ProxiCube in back area position S2 (white arrow). 
Table 1. Sensirion SPS30 sensor performance values.

\begin{tabular}{|c|c|c|c|}
\hline Parameter & Conditions & Value & Units \\
\hline Mass concentration range & - & 0 to 1000 & $\mu \mathrm{g} \mathrm{m}^{-3}$ \\
\hline Number concentration range & - & 0 to 3000 & $\mathrm{P} \mathrm{cm}^{-3}$ \\
\hline \multirow[t]{5}{*}{ Size range } & PM0.5 & 0.3 to 0.5 & $\mu \mathrm{m}$ \\
\hline & PM1.0 & 0.3 to 1.0 & $\mu \mathrm{m}$ \\
\hline & PM2.5 & 0.3 to 2.5 & $\mu \mathrm{m}$ \\
\hline & PM4 & 0.3 to 4.0 & $\mu \mathrm{m}$ \\
\hline & PM10 & 0.3 to 10.0 & $\mu \mathrm{m}$ \\
\hline \multirow[t]{2}{*}{$\begin{array}{l}\text { Mass concentration precision for } \\
\text { PM1 and PM2.5 }\end{array}$} & 0 to $100 \mu \mathrm{g} \mathrm{m}^{-3}$ & \pm 10 & $\mu g \mathrm{~m}^{-3}$ \\
\hline & 100 to $1000 \mu \mathrm{g} \mathrm{m}^{-3}$ & \pm 10 & $\% \mathrm{~m} . \mathrm{v}$. \\
\hline \multirow{2}{*}{$\begin{array}{l}\text { Mass concentration precision for } \\
\text { PM4 and PM10 }\end{array}$} & 0 to $100 \mu \mathrm{g} \mathrm{m}^{-3}$ & \pm 25 & $\mu \mathrm{g} \mathrm{m}^{-3}$ \\
\hline & 100 to $1000 \mu \mathrm{g} \mathrm{m}^{-3}$ & \pm 25 & $\% \mathrm{~m} . \mathrm{v}$. \\
\hline \multirow[t]{2}{*}{$\begin{array}{l}\text { Number concentration precision for } \\
\text { PM0.5, PM1 and PM } 2.5\end{array}$} & 0 to $1000 \mathrm{P} \mathrm{cm}^{-3}$ & \pm 100 & $\mathrm{P} \mathrm{cm}^{-3}$ \\
\hline & 1000 to $3000 \mathrm{P} \mathrm{cm}^{-3}$ & \pm 10 & $\% \mathrm{~m} . \mathrm{v}$. \\
\hline \multirow{2}{*}{$\begin{array}{l}\text { Number concentration precision for } \\
\text { PM4 and PM10 }\end{array}$} & 0 to $1000 \mathrm{P} \mathrm{cm}^{-3}$ & \pm 250 & $\mathrm{P} \mathrm{cm}^{-3}$ \\
\hline & 1000 to $3000 \mathrm{P} \mathrm{cm}^{-3}$ & \pm 25 & $\% \mathrm{~m} . \mathrm{v}$. \\
\hline
\end{tabular}

The ProxiCube NX 3 device in the pre-production ProxiCube-p design was validated by performing reference laboratory measurements [22]. Results confirmed this device to be suitable for use in the specific setting of our field experimental study to investigate total aerosol burden.

\subsection{Variables, Data Collection and Analysis}

Table 2 shows the six experimental cases under study. The leftmost column presents the abbreviation for the variables used later in the text. An " $X$ " signifies that the tabulated intervention or condition was applied in the respective case. An empty box signifies that the intervention or condition described was not applied.

Total aerosol burden in $\mu \mathrm{g} / \mathrm{m}^{3}$ measured at front area position $\mathrm{S} 1$ and total aerosol burden measured at back area position S2 represented the dependent variables of the study

Prior to study, reducing crew size and wearing face-masks were generally recommended and published by the German occupational safety agency Deutsche gesetzliche Unfallversicherung (DGUV) [23]. Case 1 is considered a reference case with applying no explanatory COVID-19 safety interventions while case 6 represents a potential maximum safety case applying all COVID-19 safety interventions tested in this study.

In every case we investigated a different combination of explanatory variables (COVID-19 safety interventions). Explanatory variables included a standard tactical crew size of nine persons, a reduced tactical crew size of six persons, no respiratory protection of crew in cabin and respiratory protection of crew in cabin using FFP2 respirators, donning and not donning of a disconnected SCBA full-face mask on seats 3, 5, 7 and 8, respectively.

Control variables were vehicle speed of $35 \mathrm{~km} / \mathrm{h}$, speaking and crew activity in the cabin. Speaking in cabin was standardized using a script. Crew activity was standardized as donning a fire hood and the SCBA high-pressure tank, and gathering a handheld radio terminal, a hand lamp and a thermal camera on seats $3,5,7$ and 8 with crew members on seats 4,6 and 9 assisting them according to a standardized scripted procedure. Scripts are included in Appendices A and B for experimental cases with 9 and 6 persons, respectively. Prior to these experiments, speaking and activity scripts were trained by the crew, and the fire engine's captain monitored full compliance to scripts on board. Additional control variables included air temperature in cabin in ${ }^{\circ} \mathrm{C}$, air pressure in cabin in mbar and absolute humidity in cabin in $\mathrm{kg} / \mathrm{m}^{3}$ as measured with the two ProxiCube-p pre-production devices in positions $\mathrm{S} 1$ and $\mathrm{S} 2$, respectively. 
Table 2. Experimental settings and results.

\begin{tabular}{|c|c|c|c|c|c|c|c|}
\hline & Experimental Cases & 1 & 2 & 3 & 4 & 5 & 6 \\
\hline & Start Time & 10:56:03 & 11:51:14 & 13:33:21 & 11:23:55 & 13:05:51 & 13:59:56 \\
\hline & End time & 11:11:05 & 12:06:16 & 13:48:23 & 11:38:57 & 13:20:53 & 14:14:58 \\
\hline \multicolumn{8}{|c|}{ Explanatory variables (COVID-19 safety interventions) } \\
\hline CS9 & Standard tactical crew size on seats 1 to 9 & $x$ & $x$ & $x$ & & & \\
\hline CS6 & Reduced tactical crew size on seats $1-3,5,7$ and 8 only & & & & $x$ & $\mathrm{x}$ & $\mathrm{x}$ \\
\hline NOR & No respiratory protection of crew in cabin & $\mathrm{x}$ & & & $x$ & & \\
\hline REP & Respiratory protection of crew in cabin using FFP2 respirators & & $x$ & $x$ & & $x$ & $x$ \\
\hline DOF & Donning of SCBA fullface mask in cabin & $\mathrm{x}$ & $\mathrm{x}$ & & $x$ & $x$ & \\
\hline NOF & Not donning on of SCBA fullface mask in cabin & & & $\mathrm{x}$ & & & $\mathrm{x}$ \\
\hline \multicolumn{8}{|c|}{ Dependent variables at front area position $\mathrm{S} 1$} \\
\hline AS1_05 & Arithm. mean of total aerosol in $\mu \mathrm{g} / \mathrm{m}^{3}$ at S1 during $1-5 \mathrm{~min}$ & 108.5 & 82.1 & 55.3 & 88.4 & 70.2 & 74.7 \\
\hline AS1_10 & Arithm. mean of total aerosol in $\mu \mathrm{g} / \mathrm{m}^{3}$ at $\mathrm{S} 1$ during $1-10 \mathrm{~min}$ & 98.4 & 75.1 & 60.4 & 80.3 & 69.3 & 70.5 \\
\hline AS1_15 & Arithm. mean of total aerosol in $\mu \mathrm{g} / \mathrm{m}^{3}$ at S1 during $1-15 \mathrm{~min}$ & 91.9 & 74.8 & 61.8 & 75.3 & 67.3 & 70.2 \\
\hline & Change \% & -15.3 & -9.0 & 11.8 & -14.8 & -4.1 & -6.0 \\
\hline \multicolumn{8}{|c|}{ Dependent variables at back area position S2 } \\
\hline AS2_05 & Arithm. mean of total aerosol in $\mu \mathrm{g} / \mathrm{m}^{3}$ at S2 during $1-5 \mathrm{~min}$ & 98.8 & 73.6 & 50.7 & 82.4 & 63.9 & 66.2 \\
\hline AS2_10 & Arithm. mean of total aerosol in $\mu \mathrm{g} / \mathrm{m}^{3}$ at S2 during $1-10 \mathrm{~min}$ & 87.8 & 71.5 & 56.7 & 73.7 & 66.1 & 65.2 \\
\hline AS2_15 & Arithm. mean of total aerosol in $\mu \mathrm{g} / \mathrm{m}^{3}$ at S2 during $1-15 \mathrm{~min}$ & 83.3 & 72.0 & 58.4 & 71.2 & 64.7 & 65.6 \\
\hline & Change \% & -15.7 & -2.2 & 15.3 & -13.5 & 1.1 & -0.9 \\
\hline \multicolumn{8}{|c|}{ Control variables } \\
\hline VES & Vehicle speed $35 \mathrm{~km} / \mathrm{h}$ & $\mathrm{x}$ & $x$ & $\mathrm{x}$ & $\mathrm{x}$ & $x$ & $x$ \\
\hline STA & Standardized activity of crew in cabin according to script & $x$ & $x$ & $x$ & $x$ & $\mathrm{x}$ & $x$ \\
\hline STS & Standardized speaking of crew in cabin according to script & $\mathrm{x}$ & $x$ & $x$ & $x$ & $\mathrm{x}$ & $x$ \\
\hline \multicolumn{8}{|c|}{ Control variables at front area position $\mathrm{S} 1$} \\
\hline MIT1 & Minimum temperature ${ }^{\circ} \mathrm{C}$ at $\mathrm{S} 1$ & 17.2 & 22.5 & 21.4 & 19.8 & 24.0 & 22.6 \\
\hline MAT1 & Maximum temperature ${ }^{\circ} \mathrm{C}$ at $\mathrm{S} 1$ & 23.2 & 27.9 & 27.4 & 25.6 & 28.7 & 28.2 \\
\hline MIH1 & Minimum absolute humidity in $\mathrm{kg} / \mathrm{m}^{3}$ at $\mathrm{S} 1$ & 0.0167 & 0.0146 & 0.0175 & 0.0158 & 0.0158 & 0.0163 \\
\hline MAH1 & Maximum absolute humidity in $\mathrm{kg} / \mathrm{m}^{3}$ at $\mathrm{S} 1$ & 0.0208 & 0.0180 & 0.0216 & 0.0195 & 0.0188 & 0.0196 \\
\hline MIP1 & Minimum air pressure in mbar at $\mathrm{S} 1$ & 1002 & 1002 & 1001 & 1002 & 1001 & 1000 \\
\hline MAP1 & Maximum air pressure in mbar at $\mathrm{S} 1$ & 1003 & 1002 & 1002 & 1002 & 1002 & 1001 \\
\hline \multicolumn{8}{|c|}{ Control variables at back area position S2 } \\
\hline MIT2 & Minimum temperature ${ }^{\circ} \mathrm{C}$ at $\mathrm{S} 2$ & 20.0 & 25.6 & 24.4 & 24.1 & 26.6 & 26.0 \\
\hline MAT2 & Maximum temperature ${ }^{\circ} \mathrm{C}$ at $\mathrm{S} 2$ & 24.8 & 29.6 & 29.3 & 27.8 & 29.8 & 30.2 \\
\hline MIH2 & Minimum absolute humidity in $\mathrm{kg} / \mathrm{m}^{3}$ at $\mathrm{S} 2$ & 0.0146 & 0.0123 & 0.0146 & 0.0119 & 0.0135 & 0.0134 \\
\hline MAH2 & Maximum absolute humidity in $\mathrm{kg} / \mathrm{m}^{3}$ at $\mathrm{S} 2$ & 0.0199 & 0.0156 & 0.0193 & 0.0158 & 0.0165 & 0.0161 \\
\hline MIP2 & Minimum air pressure in mbar at S2 & 1001 & 1001 & 1000 & 1001 & 1001 & 1000 \\
\hline MAP2 & Maximum air pressure in mbar at $\mathrm{S} 2$ & 1002 & 1002 & 1001 & 1002 & 1001 & 1001 \\
\hline
\end{tabular}

We measured total aerosol burden, cabin air temperature, absolute humidity and cabin air pressure every $11 \mathrm{~s}$ at $\mathrm{S} 1$ and S2 from start to end of each 15-min experimental case. Thus, we produced 83 data points in each sensor position for each of these eight variables, respectively. Data were acquired using the two validated ProxiCube NX 3 devices in the ProxiCube-p pre-production design.

Data were transmitted in real-time from the two ProxiCube-p devices to a central data repository (Pfalzkom Datacenter, Mutterstadt, Germany) using Wireless Local Area Network (WLAN) and Long Term Evolution (LTE) technology. Subsequently, data were analyzed using Microsoft Excel 2019 (Microsoft Corporation, Albuquerque, NM, USA).

\subsection{Experimental Procedure}

Against the background of today's German fire service system and geographical allocation of fire stations, a five-minute driving period is considered to occur in a majority 
of emergency calls. Upon alert, German fire service performance guidelines for fighting fires in residential buildings require the first standard fire engine to arrive at the incident site after no longer than ten minutes and the second standard fire engine to arrive after no longer than $15 \mathrm{~min}$ [24]. Therefore, we investigated dependent, explanatory and control variables in three intervals: during the first five minutes, during the first ten minutes, and during the entire $15 \mathrm{~min}$ of each experimental case.

Experimental cases were performed on Sunday, 21 March 2021 between 10:56 h and 14:14 h (UTC+1) in 68,549 Ilvesheim, Germany, on a standardized driving route on public streets. Weather conditions during the experimental period were observed as follows: cloudy, temperature between 5.4 and $9.6{ }^{\circ} \mathrm{C}$, relative humidity between 55 and $67 \%$, and moderate to no wind from the southwest. During experimental case 2, we encountered light rain or drizzle.

Before the start of the first experimental case, every study participant underwent a swab for PCR testing and a blood draw for antibody testing. After the health test results were available, we assigned seat positions 1 (captain) and 2 (driver) to two study participants with the required qualification and randomized the remainder of study participants to seat positions 3 to 9. This initial assignment of participants to seat positions 1 to 9 remained constant throughout the study.

Prior to the start of every experimental case, the four doors of the empty cabin were kept fully open for $10 \mathrm{~min}$ outside the fire station.

After proceeding to assigned cabin seats in a fire drill manner, we closed the cabin doors, immediately accelerated the fire engine to $35 \mathrm{~km} /$ and kept this speed until the end of experiment. Each experimental period ranged from 00:00 $\mathrm{min}$ (closing of doors) to 15:02 min. In cases 1 to 6 the COVID-19 safety interventions under study were applied as indicated in Table 2.

After the completion of every 15-min experimental period, the fire engine was stopped in front of the fire station, SCBA full-face masks were taken off again, SCBA high-pressure tanks and all other equipment were made ready for use again, and study participants left the cabin. Thereafter all cabin doors were kept fully open again for $10 \mathrm{~min}$.

In experimental cases with FFP2 respirator use, these were put on just prior to proceeding to cabin seats and proper fit was tested according to instructions for use. Three FFP2 respirators were marked with both a personalized code and a consecutive number and were provided to each study participant for rolling exchange between experimental cases. Thus, an FFP2 respirator used for $15 \mathrm{~min}$ in a previous experimental case was hung up in the fire station to dry and air for $60 \mathrm{~min}$ before being used again.

In experimental cases 1, 2, 4 and 5, participants on seat positions 3, 5, 7 and 8 took off their FFP2 mask and subsequently put on a fire-resistant hood, a high-pressure tank, an SCBA full-face mask and other equipment. The SCBA full-face mask was not connected to the SCBA high-pressure tank. Consequently, they continued breathing cabin air without any respiratory protection. In cases 3 and 6 these participants did not put on the SCBA full-face mask but continued using their FFP2 mask instead.

\section{Results}

\subsection{Comparative Overview}

All experiments were carried out as scheduled on 21 March 2021. Table 2 provides a comparative overview of experimental cases in front area position S1 and in back area position S2.

Table 2 includes real-time (UTC +1$)$, arithmetic mean values of total aerosol burden in $\mu \mathrm{g} / \mathrm{m}^{3}$ during the first $5 \mathrm{~min}$, during the first $10 \mathrm{~min}$ and during the entire $15 \mathrm{~min}$ of experimental cases. We also indicated the change within each experimental case from AS1_05 to AS1_15 and from AS2_05 to AS2_15 in \%. Moreover, minimum and maximum values of control variables are included. 
In order to allow for a paired comparative analysis of safety interventions, associated aerosol burden and spread of values across all experimental cases and periods, we chose boxplots for data analysis.

Figures 4-6 present a comparative boxplot overview of total aerosol burden in $\mu \mathrm{g} / \mathrm{m}^{3}$ during the first $5 \mathrm{~min}$, during the first $10 \mathrm{~min}$ and during the entire $15 \mathrm{~min}$ of experimental cases as measured at front area position S1 and back area position S2. The box includes the middle $50 \%$ of all data points. The lower end of the box marks the first $25 \%$ of data points (first quartile). The upper end of the box marks the first $75 \%$ of data points (third quartile) and the median is marked in between. The cross in each box indicates the arithmetic mean of data points (83 in $15 \mathrm{~min}$. period) measured for each case. Potential maximum length of whiskers equals 1.5 times of the interquartile range. Points above or below whiskers mark statistical outliers. The red dotted line marks the arithmetic mean of total aerosol as measured for reference case 1 with no COVID-19 safety intervention.

\subsection{Results in Front Area}

As revealed in Table 2, and Figure 4 to Figure 6 for S1, during the first 5 min the largest decrease of the arithmetic mean of total aerosol compared to reference case 1 with $108.5 \mu \mathrm{m} / \mathrm{m}^{3}$ was recognized in case 3 with $55.3 \mu \mathrm{m} / \mathrm{m}^{3}$. This equals a reduction of $-49 \%$. During the first 10 and during the entire $15 \mathrm{~min}$, the largest reduction was also detected in case 3 . These reductions equaled -39 and $-33 \%$, respectively.

The second largest decrease versus reference case 1 was discovered for case 5 with a reduction of $-35,-30$ and $-27 \%$ during the first 5,10 and $15 \mathrm{~min}$, respectively. The smallest decrease against reference case 1 was reported for case 4 with a reduction of -19 , -18 and $-18 \%$ during the first 5, 10 and 15 min, respectively.

When looking at changes between AS1_05 and AS1_15 in each of the experimental cases in Table 2, these changes ranged from a decrease of $-15 \%$ in case 1 to an increase of $+12 \%$ in case 3 . We observed cabin air temperatures from 17.2 in case 1 up to 28.7 degrees Celsius in case 5, and absolute humidity was seen from 0.0146 in case 2 up to $0.0216 \mathrm{~kg}$ per cubic meter in case 3 . The minimum of cabin air pressure was 1000 in case 6 and the maximum was 1003 millibar in case 1.

Total Aerosol measured from minute 1 to 5

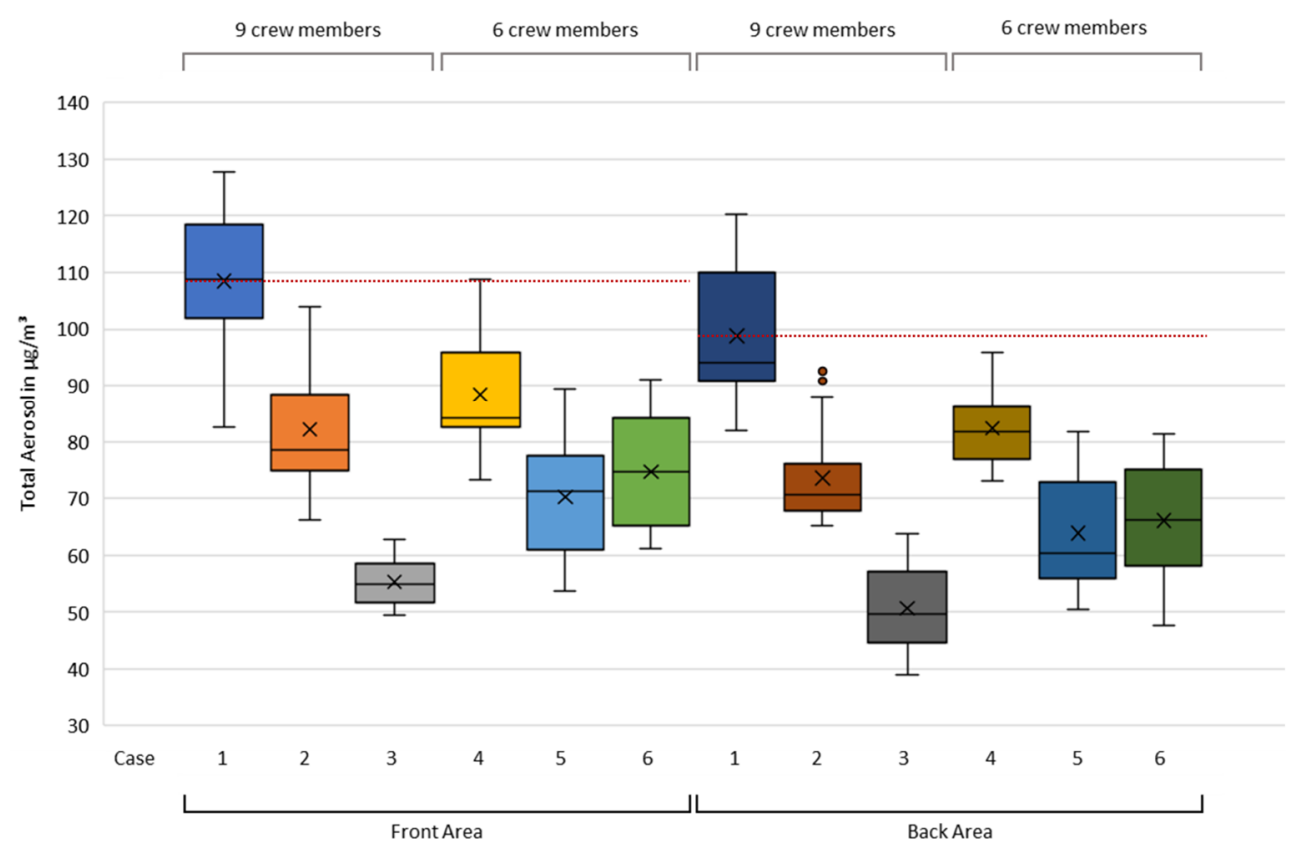

Figure 4. Total aerosol burden measured from minute 1 to 5. 
Total Aerosol measured from minute 1 to 10

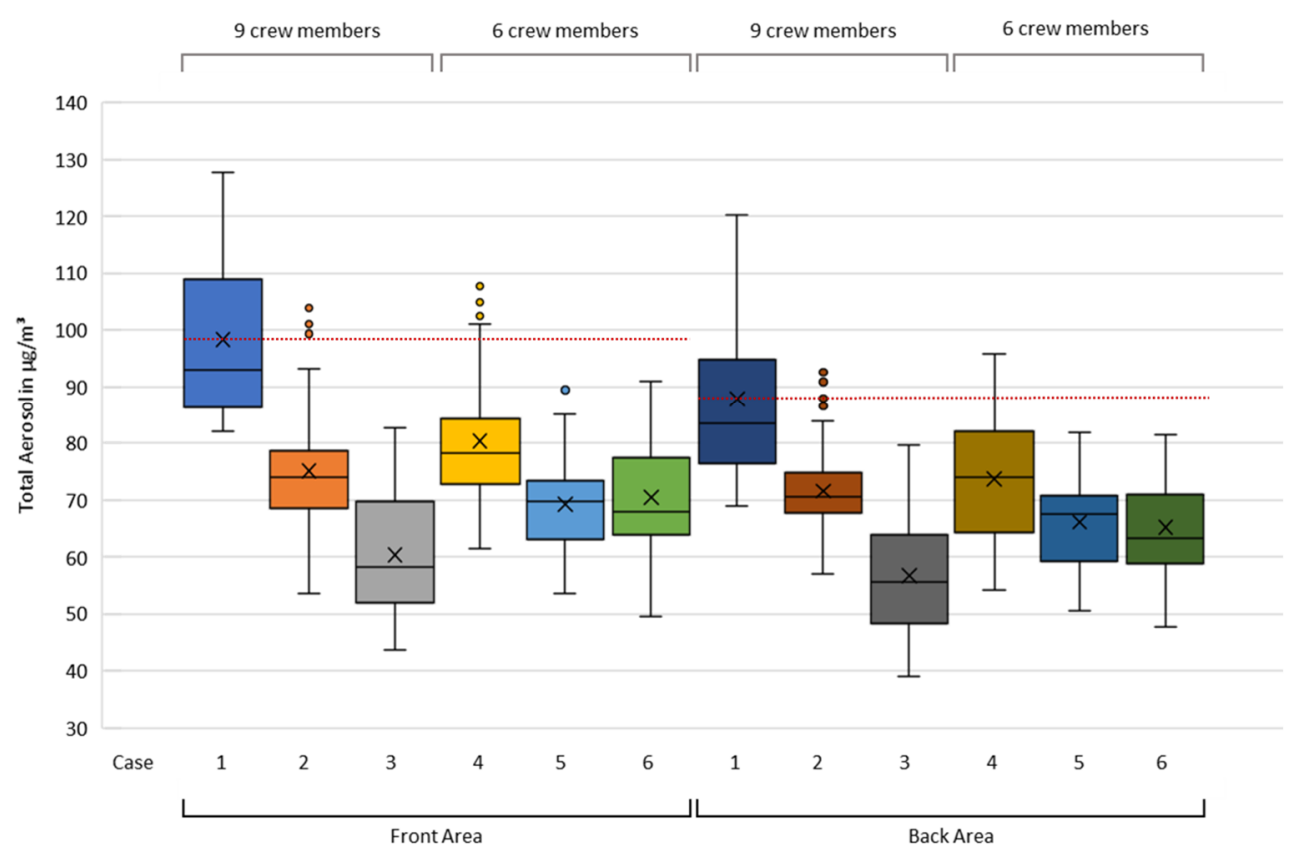

Figure 5. Total aerosol burden measured from minute 1 to 10.

Total Aerosol measured from minute 1 to 15

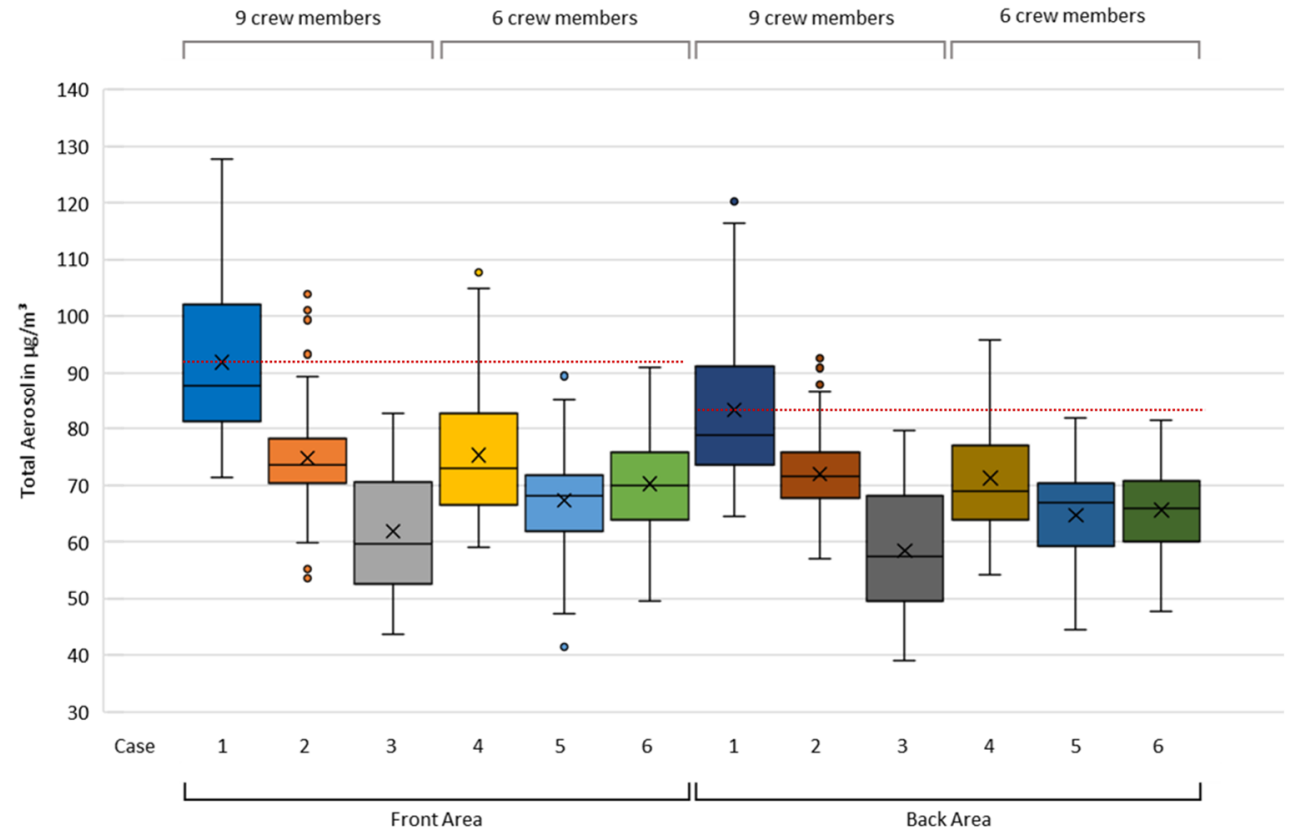

Figure 6. Total aerosol burden measured from minute 1 to 15.

\subsection{Results in Back Area}

As shown in Table 2 and Figure 4 to Figure 6 for S2, during the first 5 min the largest decrease of the arithmetic mean of total aerosol compared to reference case 1 with $98.8 \mu \mathrm{m} / \mathrm{m}^{3}$ was recognized in case 3 with $50.7 \mu \mathrm{m} / \mathrm{m}^{3}$. This equals a reduction of $-49 \%$. During the first 10 and during the entire $15 \mathrm{~min}$, the largest reduction was also detected in case 3 . Reductions equaled -35 and $-30 \%$, respectively.

The second largest decrease versus reference case 1 was recorded for cases 5 and 6 . For these two cases we observed comparable reductions of -35 , and $-33 \% \%$ during the 
first five minutes, -25 and $-26 \%$ during the first $10 \mathrm{~min}$, and -22 and $-21 \%$ during the entire $15 \mathrm{~min}$, respectively.

The smallest decrease against reference case 1 was reported for case 4 during the first 5 and the first 10 min with a reduction of -17 and $-16 \%$, respectively. During the entire $15 \mathrm{~min}$, this changed and we observed comparable reductions for cases 2 and 4 with -14 and $-15 \%$ versus reference case 1 .

When analyzing changes between AS2_05 and AS2_15 in each of the experimental cases of Table 2, these changes ranged from a decrease of $-16 \%$ in case 1 to an increase of $15 \%$ in case 3 . Furthermore, we observed cabin air temperatures from 20.0 in case 1 to 30.2 degrees Celsius in case 6, and absolute humidity was seen from 0.0119 in case 4 to $0.0199 \mathrm{~kg}$ per cubic meter in case 1. The minimum of cabin air pressure was 1000 in two cases and the maximum was 1002 millibar in three cases, as displayed in Table 2.

\subsection{Observations Related to Both, Front and Back Area}

The captain of the fire engine reported minor changes of environmental conditions and minor events non-compliant to the study protocol as presented in Table 3.

Table 3. Changes of environmental conditions and events non-compliant to the study protocol.

\begin{tabular}{|c|c|c|c|c|c|}
\hline \multirow{2}{*}{ Case } & \multirow{2}{*}{$\begin{array}{l}\text { Start Time } \\
\text { of Experiment }\end{array}$} & \multicolumn{2}{|c|}{ Event Observed } & \multirow{2}{*}{ Description of Event } & \multirow{2}{*}{$\begin{array}{l}\text { End Time } \\
\text { of Experiment }\end{array}$} \\
\hline & & From & To & & \\
\hline 1 & $10: 56: 03$ & - & - & no event reported & 11:11:05 \\
\hline \multirow{2}{*}{2} & $11: 51: 14$ & $11: 51: 26$ & $11: 51: 30$ & $\begin{array}{l}\text { stop of fire engine at stop sign or traffic } \\
\text { light for } 4 \mathrm{~s}\end{array}$ & $12: 06: 16$ \\
\hline & $11: 51: 14$ & $11: 51: 14$ & $12: 06: 16$ & $\begin{array}{l}\text { light rain or drizzle during entire } \\
15: 02 \text { experimental period }\end{array}$ & $12: 06: 16$ \\
\hline 3 & $13: 33: 21$ & $13: 35: 52$ & $13: 35: 56$ & $\begin{array}{l}\text { stop of fire engine at stop sign or traffic } \\
\text { light for } 4 \mathrm{~s}\end{array}$ & $13: 48: 23$ \\
\hline 4 & $11: 23: 55$ & $11: 26: 13$ & $11: 26: 24$ & $\begin{array}{c}\text { stop of fire engine at stop sign or traffic } \\
\text { light for } 11 \mathrm{~s}\end{array}$ & $11: 38: 57$ \\
\hline 5 & $13: 05: 51$ & - & - & no event reported & $13: 20: 53$ \\
\hline 6 & $13: 59: 56$ & 14:02:09 & $14: 02: 19$ & $\begin{array}{c}\text { stop of fire engine at stop sign or traffic } \\
\text { light for } 10 \mathrm{~s}\end{array}$ & $14: 14: 58$ \\
\hline
\end{tabular}

\section{Discussion}

We used two independent, validated sensors of the same type to measure dependent and control variables at the same time at different positions in the middle plane of the cabin, albeit at different heights within the cabin. Therefore, we considered our collected raw data to be robust. However, our dynamic field experiment may have included a variety of human, technical and environmental variables of potential influence that we were not able to manipulate or control for. Consequently, a spread of data was expected and seen in each experimental case. Nevertheless, with our sampling of fire engine and crew, and our standardization of explanatory variables and technical settings as described further above, we consider our results reliable and valid as it relates to the aim of our study.

\subsection{Overall Comparison of Experimental Cases}

Our investigation included six experimental cases. Case 1 represented a reference case while applying none of the safety interventions under study. Each of the further cases 2 to 6 included a different combination of safety interventions as was described in Table 2. In case 6, we applied all safety interventions of the study. From a general perspective, when compared to case 1, all other cases were associated with a lower arithmetic mean of total aerosol. 
Figures 4-6 revealed that cases 1, 2 and 3 (blue, orange and light grey, respectively) form a cascade pattern (i.e., a single safety intervention applied was associated with a substantial decrease of aerosol burden), while applying an additional safety intervention, all other things equal, was associated with an additional substantial decrease of aerosol burden.

More specifically, we noticed in Figure 4 to Figure 6 that the lowest total aerosol burden was associated with case 3 (light grey and dark grey). Case 3 comprised the use of FFP2 respirators and not donning SCBA full-face masks, while nine crew members were on board and windows were closed. We consider this result remarkable, as we initially expected case 6 to be associated with the lowest aerosol burden.

If not applicable in a specific emergency response situation, e.g., due to an organizational restriction to 6 crew members, then safety interventions as applied in cases 5 (blue, dark blue) and 6 (green, dark green) might be considered as an alternative option.

\subsection{Aspects of Not Donning SCBA}

As can be derived from case 3 in Table 2, with a standard tactical crew size of nine persons, the single effect size of not donning SCBA full-face masks seems to approximately equal the single effect size of FFP2 use, resulting in a combined total effect size of up to $-49 \%$ at position S1 and up to $-49 \%$ at position S2. This appears conclusive, since in case 3 the four SCBA users out of the nine crew members did not breath unfiltered cabin air but continued wearing FFP2 respirators, like all other crew members did.

As previously mentioned, donning SCBA full-face masks in the cabin, but keeping them disconnected from the SCBA high-pressure tank during response, is seen as a common practice to gain life-saving time. In light of our initial evidence, practitioners may reconsider the risks and benefits of common SCBA practice and review alternative practice standards for emergency calls with required SCBA use.

\subsection{Aspects of Reducing Crew Size}

Table 2 as well as Figure 4 to Figure 6 reveal more specific detail on the effectiveness of reducing crew size.

Associations of a reduced tactical crew size of six persons and a decrease of total aerosol burden were detected in Figure 4 to Figure 6 for cases 4 and 5 when compared to their corresponding cases 1 and 2 . This suggests that a reduction of crew size from nine to six persons might be effective to reduce potential transmission of SARS-CoV-2. This appears to be generally conclusive, since a reduction of crew size creates more cabin air volume and, in principle, leads to less emission of aerosol.

However, the effectiveness of reducing crew size seemed also to be reversed through the additional not donning of SCBA full-face masks, as can be seen in corresponding cases 3 (grey, dark grey) and 6 (green, dark green). In principle, not donning SCBA full-face masks leads to less crew activity and to less aerosol emission as the four crew members on seats 3, 5, 7 and 8 are less active, and continue using their FFP2 masks instead of breathing unfiltered air through disconnected SCBA full-face masks. Therefore, we found this observation inconclusive. Further research is needed to investigate this specific issue.

\subsection{Aspects of Mechanical Ventilation}

Table 2 revealed how the arithmetic mean of total aerosol changed in each case when comparing the first $5 \mathrm{~min}$ to the entire 15-min experimental period. In the front area position S1 these changes ranged from -15 to $12 \%$ and in back area position S2 from -16 to $15 \%$. In cases 2, 5 and 6 we noticed little to no change at sensor position S2. The direction and the size of these changes within each experimental case do not appear to correspond substantially to any of our explanatory or control variables, and, thus might be subject to other human, technical and environmental variables of potential influence.

As shown in Appendix C, selected data for the partial periods from minute 6 to 10, and from minute 11 to 15 revealed the effectiveness of safety interventions may generally 
decrease over time. This might result from a continuous air flow through the fire engine cabin created by the mechanical ventilation, which was set to $50 \%$ power, fresh air inlet and to instrument panel/windshield outlet. Consequently, our finding supports the use of these specific ventilation settings in a fire engine.

\subsection{Environmental Factors and Non-Compliant Events}

Air pressure in the cabin ranged from 1000 to 1003 mbar, air temperature in cabin ranged from 17.2 to $30.2{ }^{\circ} \mathrm{C}$ and absolute humidity in cabin ranged from 0.0119 to $0.0216 \mathrm{~kg} / \mathrm{m}^{3}$ across all experimental cases. Recent evidence suggests that different levels of humidity potentially facilitate the airborne transmission of SARS-CoV-2 through aerosols in indoor situations [25]. When comparing values of total aerosol burden to values of these three control variables on a case-by-case basis, the variances of these three control variables seemed too small for causal relationships with total aerosol burden as measured. When analyzing the environmental changes and the non-compliant events reported in Table 3, we considered these changes and events to be negligible.

\subsection{Effectiveness and Implications of Safety Interventions}

As mentioned above, there are insufficient reliable data to determine a critical concentration of infectious virus and a corresponding critical time period of exposure to exclude an airborne transmission of SARS-CoV-2 [18]. However, a situation like the cabin of a fire engine responding to an emergency is defined as a high-risk exposure to a SARS-CoV-2 infection through aerosols [13]. Therefore, we considered effect sizes of different safety interventions to reduce aerosol burden in the cabin as a meaningful surrogate parameter for the reduction of potential airborne transmission of SARS-CoV-2.

In summary, we found the use of FFP2 respirators and not donning SCBA full-face masks might be effective to substantially reduce total aerosol burden if windows are closed, mechanical ventilation is switched to $50 \%$ power, fresh air inlet, and outlet is set to instrument panel/windshield.

Our findings may be generalizable to the use of other respirators following performance standards N95 (United States NIOSH-42CFR84), KN95 (China GB2626-2006), P2 (Australia/New Zealand AS/NZA 1716:2012), Korea 1st class (Korea KMOEL-2017-64), DS2 (Japan JMHLW-Notification 214, 2018) and PFF2 (ABNT/NBR 13.698-2011-Brazil) [26].

Moreover, we found the reduction of tactical crew size to six persons might be effective with or without the use of FFP2 respirators if windows are closed, mechanical ventilation is switched to $50 \%$ power, fresh air inlet and outlet is set to instrument panel/windshield. The effectiveness of additionally not donning SCBA full-face masks in this specific setting remained unclear.

Our findings appear to be partially in contrast to current guidelines from German fire service authorities, from healthcare authorities and from occupational safety agencies. To date, these bodies generally recommend a reduction of the tactical crew size in fire engines, while donning of SCBA full-face masks during approach has not been scrutinized yet.

\subsection{Limitations of This Study}

We conducted our field experimental study in a critical pandemic and high-risk exposure situation. The massive human, technical, medical and operational resources required to perform experiments according to safety and ethical standards were available for no longer than one single day. Therefore, we were not able to investigate more variations of safety interventions and parameter settings. Further limitations include, but are not limited to, small dataset size, measurement of total aerosol burden rather than liquid aerosol burden and environmental variables of potential influence that we were not able to manipulate or to control for. Making these measurements in an actual emergency setting under reproducible conditions is extremely challenging and sometimes surprising since the obvious candidate safety interventions of case 6 had either no or no consistent effect reducing total aerosol burden. 


\section{Conclusions}

Keeping a minimum distance and using face coverings are considered key interventions to reduce the airborne transmission of coronavirus SARS-CoV-2 through aerosols and thus, to prevent COVID-19. These interventions are difficult to implement for millions of firefighters during an emergency response. Furthermore, a variety of additional COVID-19 safety interventions in such a setting is emerging in firefighting practice, while the delayed forthcoming of evidence on the effectiveness of these practices is considered a major problem.

To the best of these authors' collective knowledge, there has been no data available on the association of the safety interventions examined in this study and total aerosol burden in fire engines responding to an emergency call. In this field experimental study, we collected unique new data that supports closing of this gap. Our empirical investigation has established implications for both research and practitioners.

From a research perspective, our data suggests that certain combinations of COVID-19 safety interventions in fire engines might be effective to reduce the total aerosol burden and, thus, the potential airborne transmission of SARS-CoV-2.

From a practitioner's perspective, this study is a call to action for reviewing COVID-19 safety interventions in fire engines as practiced to date. Results may provide initial guidance for decision makers in firefighting practice, but also in similar organizational and vehicle settings, like e.g., in civil protection services, emergency medical services, police and military services.

Considering the risk associated with future coronavirus variants, future influenza virus variants and other communicable diseases with similar modes of transmission through airborne particles, this study may also support decision making in occupational medicine beyond SARS-CoV-2.

Although the data of our study can be regarded as a unique first step in establishing rational, fact-based protocols for implementing emergency response procedures, it is nonetheless subject to several limitations. More research about the physical and the clinical effectiveness of these and other COVID-19 safety interventions at the local practice level is urgently needed.

Author Contributions: Conceptualization, E.B., T.S., M.R. and A.H.; Methodology, E.B.; Software, T.S.; Validation, M.R., T.S.; Formal Analysis, E.B. and M.R.; Investigation, E.B., T.S., M.K., M.R., A.H.; Resources, E.B., T.S., M.K., M.R.; Data Curation, T.S., M.K.; Writing-Original Draft Preparation, E.B.; Writing—Review \& Editing, E.B., M.K., M.R., A.H.; Visualization, E.B.; Supervision, M.R., A.H.; Project Administration, E.B.; Funding Acquisition, None. All authors have read and agreed to the published version of the manuscript.

Funding: This research received no external funding.

Institutional Review Board Statement: The study was conducted according to the guidelines of the Declaration of Helsinki and approved by the Ethics Committee of Medical Faculty Mannheim of Heidelberg University (project identification code 2021-535-AF).

Informed Consent Statement: Informed consent was obtained from all subjects involved in the study.

Data Availability Statement: Data are contained within the article. Further study data and further data on laboratory reference measurements are not publicly available due to privacy or ethical reasons. Depending on a specific request, and subject to both, previous approval in written of coauthors and ethical compliance, they may be made available from the corresponding author.

Acknowledgments: Measuring aerosol burden in a fire service field experiment during a historical SARS-CoV-2 pandemic presented an extraordinary challenge in this empirical investigation. Therefore, we would like to thank the study participants and their volunteer fire departments, ProxiVision GmbH, Bensheim, Germany, Nevoox Europe GmbH, Mannheim, Germany, Medical Faculty Mannheim of Heidelberg University, Mannheim, Germany and the Baden-Wuerttemberg Stiftung gGmbH, Stuttgart, Germany, for their support, and Robert L. Shoeman, Max-Planck-Institute for Medical Research, Heidelberg, Germany, for comments on the manuscript. 
Conflicts of Interest: Authors Thomas Schaefer and Matthias Raedle have been involved as a consultant and expert witness in ProxiVision $\mathrm{GmbH}$ and in Nevoox Europe GmbH. Authors Thomas Schaefer and Matthias Raedle are the inventors of the patent for the ProxiCube technology. All other authors declare no conflicts of interest.

\section{Appendix A}

Script for experimental cases 1 to 3 with standard tactical crew size of 9 persons (Translated from German original script into English for journal publication)

00:00 Entering of fire engine in fire drill manner, with FFP2 respirators already put on in experimental cases where applicable, immediate closing of doors and start.

00:30 Captain: "Sling on SCBA full-face masks!“ Crew on seats 2 to 9: Repeats simultaneously together "Sling on SCBA full-face masks!“ Crew on seats 3, 5, 7 and 8: Remove their helmet, pull on their fire-resistant hood and sling on SCBA full-face mask around their neck. Crew on seats 6 and 9: Assist crew on seats 3 and 5. Crew on seat 4: Assists crew on seats 7 and 8 .

01:00 Captain: „Put on SCBA!“ Crew on seats 2 to 9: Repeats simultaneously together „Put on SCBA!" Crew on seats 3, 5, 7 and 8: Put on their SCBA high-pressure tank and perform quick check. Crew on seats 6 and 9: Assist crew on seats 3 and 5. Crew on seat 4: Assists crew on seats 7 and 8.

03:00 Captain: „Put on SCBA full-face masks and get ready!“ Crew on seats 2 to 9: Repeats simultaneously together "Put on SCBA full-face masks and get ready!" Crew on seats 3, 5, 7 and 8: Remove FFP2 respirator (where applicable), put on their SBCA full-face mask, pull on their fire-resistant hood, put on helmet, and take up handheld radio terminal, hand lamp and thermal camera. Crew on seats 6 and 9: Assist crew on seats 3 and 5 . Crew on seat 4: Assists crew on seats 7 and 8 .

05:30 Captain: Calls up names of SCBA users for entering into SCBA-monitoring dash board. Crew on seats 3, 5, 7 and 8: Reply with their names.

06:30 Captain: Reads from e-book in moderate volume.

07:45 Captain: Hands over e-book to seat 5 and subsequently announces the experimental time at every full minute for handing over e-book to the next seat.

08:00 Seat 5 reads from e-book in moderate volume and then hands over.

09:00 Seat 4 reads from e-book in moderate volume and then hands over.

10:00 Seat 3 reads from e-book in moderate volume and then hands over.

11:00 Seat 6 reads from e-book in moderate volume and then hands over.

12:00 Seat 7 reads from e-book in moderate volume and then hands over.

13:00 Seat 8 reads from e-book in moderate volume and then hands over.

14:00 Seat 9 reads from e-book in moderate volume and then hands over.

15:00 Captain: „End of reading!”

15:02 End of experiment.

In case 3 where SCBA full-face masks were not put on, the crew was instructed accordingly just prior to the start of the experiment. Standardized speaking and activity according to script remained the same, except for putting on SCBA full-face masks. Thus, crew on seats $3,5,7$ and 8 continued using FFP2 respirators (where applicable).

\section{Appendix B}

Script for experimental cases 4 to 6 with a reduced tactical crew size of 6 persons (Translated from German original script into English for journal publication)

00:00 Entering of fire engine in fire drill manner, with FFP2 respirators already put on in experimental cases where applicable, immediate closing of doors and start.

00:30 Captain: „Sling on SCBA full-face masks!“ Crew on seats 2, 3, 5, 7 and 8: Repeats simultaneously together ",Sling on SCBA full-face masks!" Crew on seats 3, 5, 7 and 8: Remove their helmet, pull on their fire-resistant hood and sling on SCBA full-face mask around their neck. 
01:00 Captain: „Put on SCBA!“ Crew on seats 3, 5, 7 and 8: Repeats simultaneously together „Put on SCBA!“ Crew on seats 3, 5, 7 and 8: Put on their SBCA high-pressure tank and perform quick check.

03:30 Captain: „Put on SCBA full-face masks and get ready!“ Crew on seats 3, 5, 7 and 8: Repeats simultaneously together "Put on SCBA full-face masks and get ready! Crew on seats 3, 5, 7 and 8: Remove FFP2 respirator (where applicable), put on their SBCA full-face mask, pull on their fire-resistant hood, put on helmet, and take up handheld radio terminal, hand lamp and thermal camera.

06:30 Captain: Calls up names of SCBA users for entering into SCBA-monitoring dash board. Crew on seats 3, 5, 7 and 8: Reply with their names.

07:30 Captain: Reads from e-book in moderate volume.

08:45 Captain: Hands over e-book to seat 5 and subsequently announces the experimental time at every full minute for handing over e-book to the next seat.

09:00 Seat 5 reads from e-book in moderate volume and then hands over.

10:00 Seat 3 reads from e-book in moderate volume and then hands over.

11:00 Seat 7 reads from e-book in moderate volume and then hands over.

12:00 Seat 8 reads from e-book in moderate volume and then hands back to Captain.

13:00 Captain reads from e-book in moderate volume.

14:00 Captain: „End of reading-experiment continues!“

15:02 End of experiment.

In case 6 where SCBA full-face masks were not put on, the crew was instructed accordingly just prior to start of the experiment. Standardized speaking and activity according to script remained the same, except for putting on SCBA full-face masks. Thus, crew on seats $3,5,7$ and 8 continued using FFP2 respirators (where applicable).

\section{Appendix C}

Boxplots for selected partial periods.

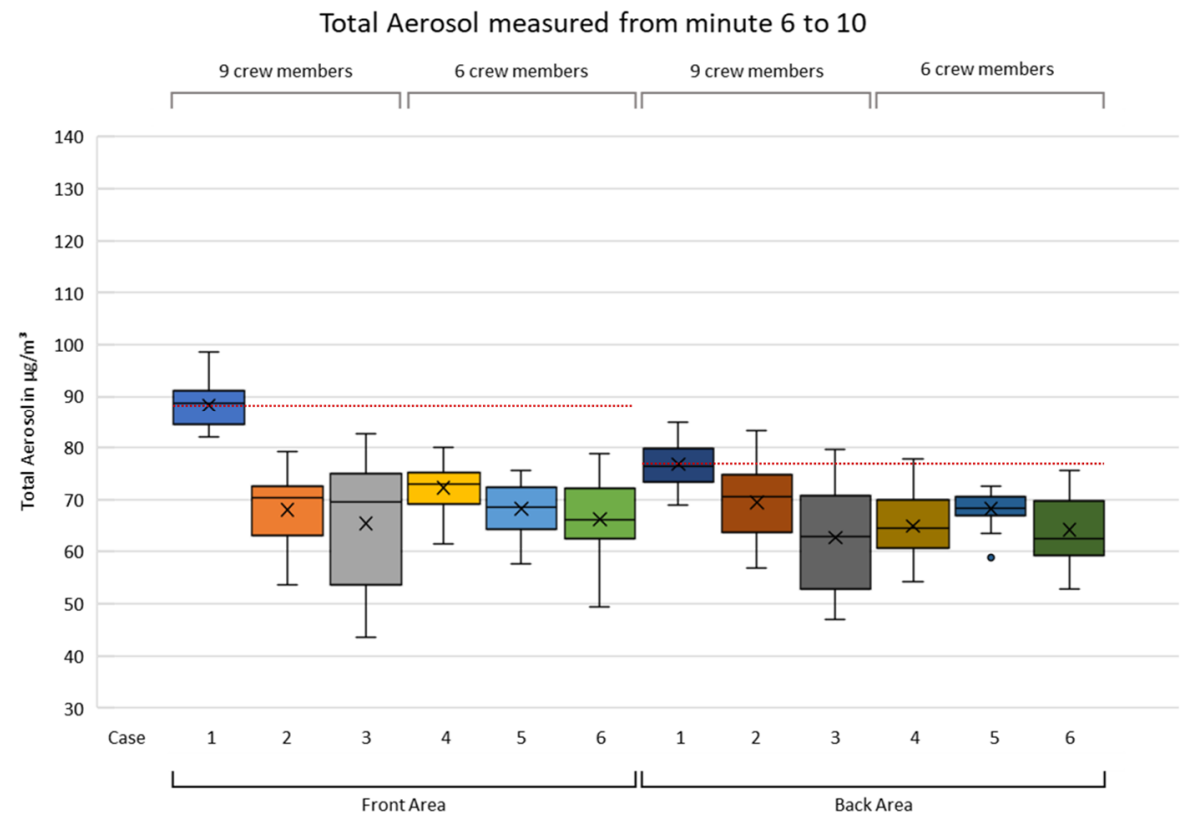

Figure A1. Total aerosol burden measured from minute 6 to 10 . 


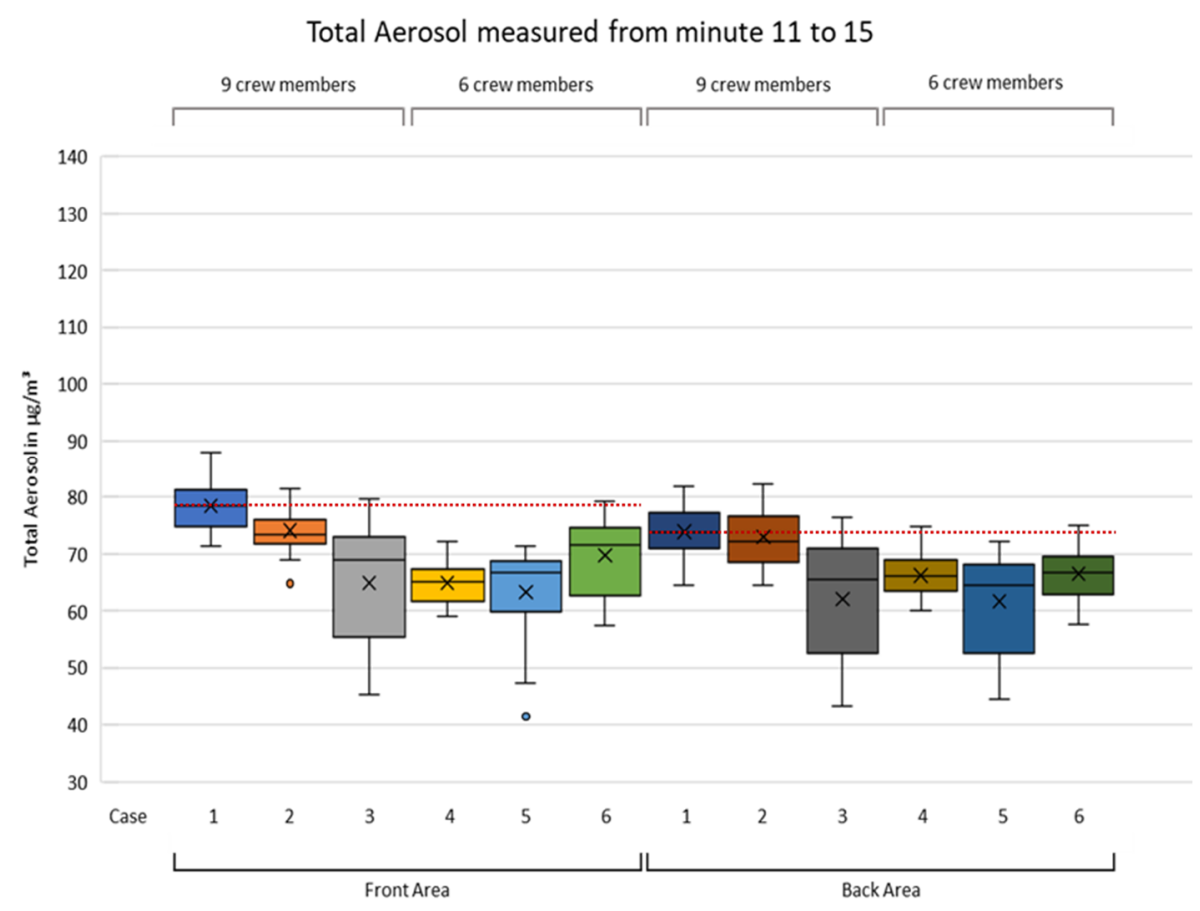

Figure A2. Total aerosol burden measured from minute 11 to 15.

\section{References}

1. World Fire Statistics. Center of Fire Statistics, International Association of Fire and Rescue Services. Available online: https://www.ctif.org/sites/default/files/2018-06/CTIF_Report23_World_Fire_Statistics_2018_vs_2_0.pdf (accessed on 10 February 2021).

2. Aktuellste Statistische Daten, Anzahl der Feuerwehren. Deutscher Feuerwehrverband. Available online: https://www feuerwehrverband.de/presse/statistik/ (accessed on 11 February 2021).

3. WHO Coronavirus (COVID-19) Dashboard. World Health Organisation. Available online: https:// covid19. who.int/ (accessed on 30 November 2021).

4. Coronavirus Disease (COVID-19): How Is It Transmitted? World Health Organisation. Available online: https://www.who.int/ news-room/q-a-detail/coronavirus-disease-covid-19-how-is-it-transmitted (accessed on 14 February 2021).

5. Meselson, M. Letter to the editor, Droplets and Aerosols in the Transmission of SARS-CoV-2. N. Engl. J. Med. 2020, $382,2063$. [CrossRef] [PubMed]

6. Prather, K.A.; Marr, L.C.; Schooley, R.T.; McDiarmid, M.A.; Wilson, M.E.; Milton, D.K. Airborne transmission of SARS-CoV-2. Science 2020, 370, 303-304. [PubMed]

7. Bazant, M.Z.; Bush, J.W.M. A Guideline to Limit Indoor Airborne Transmission of COVID-19. Proc. Natl. Acad. Sci. USA 2021, 118, e2018995118. [CrossRef] [PubMed]

8. Qian, H.; Miao, T.; Liu, L.; Zheng, X.; Luo, D.; Li, Y. Indoor transmission of SARS-CoV-2. Indoor Air 2020, 31, 639-645. [CrossRef] [PubMed]

9. Coronavirus disease (COVID-19), Weekly Epidemiological Update-2 March 2021. World Health Organisation. Available online: https:/ / www.who.int/publications/m/item/weekly-epidemiological-update-on-covid-19---30-november-2021 (accessed on 4 December 2021).

10. About Variants of the Virus that Causes COVID-19. Centers for Disease Control and Prevention. Available online: https: / / www.cdc.gov/coronavirus/2019-ncov/transmission/variant.html (accessed on 4 December 2021).

11. Kähler, C.J.; Hain, R. Fundamental protective mechanisms of face masks against droplet infections. J. Aerosol Sci. 2020, 148. Available online: https://www.sciencedirect.com/science/arti-cle/pii/S0021850220301063 (accessed on 2 March 2021). [CrossRef] [PubMed]

12. Feuerwehr-Dienstvorschrift FwDV 3, Einheiten Im Lösch-Und Hilfeleistungseinsatz. Ausschuss Feuerwehrangelegenheiten, Katastrophenschutz und zivile Verteidigung (AFKzV). 2008. p. 10. Available online: https:/ /www.lfs-bw.de/fileadmin/LFSBW/themen/gesetze_vorschriften/fwdv/dokumente/FwDV_3.pdf (accessed on 15 March 2021).

13. Technical Report, Public Health Management of Persons Having Had Contact with Cases of COVID-19 in the EU; European Center for Disease Prevention and Control: Solna, Sweden, 2020; p. 2.

14. Mathai, V.; Das, A.; Bailey, J.A.; Breuer, K. Airflows inside passenger cars and implications for airborne disease transmission. Sci. Adv. 2021, 7, eabe0166. Available online: https://advances.sciencemag.org/content/7/1/eabe0166 (accessed on 2 March 2021). 
15. Tawfik, A. COVID-19 Public Transportation Air Circulation and Virus Mitigation. Fresnostate 2020. Available online: http: / / fresnostate.edu/engineering/institutes/fsti/news/covidfsti.html (accessed on 2 March 2021).

16. Edwards, N.J.; Wilmes, W.J.; Breisch, B.; Gerschefske, M.; Sullivan, J.; Potember, R.; Espinoza-Calvio, A. Reducing COVID-19 Airborne Transmission Risks on Public Transportation Buses: An Empirical Study on Aerosol Dispersion and Control. medRxiv 2021, 1-29. [CrossRef]

17. Zhihang, Z.; Han, T.; Yoo, K.H.; Capecelatro, J.; Boehman, A.L.; Maki, K. Disease Transmission through Expiratory Aerosols on an Urban Bus. Phys. Fluids 2021, 33, 015116. Available online: https://aip.scitation.org/doi/10.1063/5.0037452 (accessed on 2 March 2021). [CrossRef] [PubMed]

18. Brockmann, S.; Dittler, A.; Grün, G.; Haibel, M.; Iftner, T.; Kräusslich, H.-G.; Mizaikoff, B.; Niessner, J.; Richter, B.; Spahn, C.; et al. Stellungnahme des „Expertenkreises Aerosole“: Aerosole und SARS-CoV-2-Entstehung, Infektiosität, Ausbreitung und Minderung luftgetragener, virenhaltiger Teilchen in der Atemluft. Gesundheitswesen 2021, 8, 231-234. Available online: https:/ / www.ncbi.nlm.nih.gov/pmc/articles/PMC8043587/ (accessed on 31 March 2021). [CrossRef] [PubMed]

19. CoVLAB Baden-Wuerttemberg: Die Mobile Corona-Teststation. Available online: https://www.covlab.de/die-teststrategie/ teststation/ (accessed on 20 April 2021).

20. DGUV Vorschrift 49, Unfallverhütungsvorschrift Feuerwehren. Deutsche Gesetzliche Unfallversicherung. June 2018. p. 14. Available online: https:/ / publikationen.dguv.de/widgets/pdf/download/article/1507 (accessed on 20 March 2021).

21. SENSIRION Particulate Matter Sensor SPS30. Available online: https://www.sensirion.com/en/environmental-sensors/ particulate-matter-sensors-pm25/ (accessed on 28 February 2021).

22. Westphal, D.; Teumer, T.; Schaefer, T.; Ahlers, R.-J.; Raedle, M. Detection and Differentiation of Liquid and Solid. Particles in Ambient Air. Chem. Ing. Technol. 2021, 93, 1-8. [CrossRef]

23. Fachbereich AKTUELL FBFHB-016: Hinweise für Einsatzkräfte zum Umgang mit bzw. zum Schutz vor dem Coronavirus SARS-CoV-2 sowie pandemiebedingte Einschränkungen; Deutsche gesetzliche Unfallversicherung (DGUV): Berlin, Germany, 2021 ; pp. 1-12.

24. Hinweise zur Leistungsfähigkeit der Feuerwehr. Innenministerium Baden-Wuerttemberg. January 2008. pp. 7-8. Available online: https://www.lfs-bw.de/fileadmin/LFS-BW/themen/gesetze_vorschriften/hinweise/dokumente/Hinweise_ Leistungsfaehigkeit_Feuerwehr.pdf (accessed on 9 February 2021).

25. Ahlawat, A.; Wiedensohler, A.; Mishra, S.K. An Overview on the Role of Relative Humidity in Airborne Transmission of SARS-CoV-2 in Indoor Environments. Aerosol Air Qual. Res. 2020, 20, 1856-1861. [CrossRef]

26. 3M, Technical Bulletin. Revision 6. February 2021. p. 1. Available online: https://multimedia.3m.com/mws/media/1791500O/ comparison-ffp2-kn95-n95-filtering-facepiece-respirator-classes-tb.pdf (accessed on 26 February 2021). 